\title{
Experimental Research and Engineering Application of Laser Cladding Reparations
}

\author{
Fu Wei \\ Shanghai Baosteel Industry technology Service Co., Ltd \\ Shanghai, China \\ e-mail: fuwei174171@baosteel.com \\ Cao Peng \\ CSIG, DCG \\ Intel Asia-Pacific Research and Development Ltd \\ Shanghai, China \\ e-mail: caopeng666@gmail.com \\ Shanghai Jiao Tong University
}

\author{
Deng Qilin \\ School of Mechanical and Power Engineering \\ Shanghai, China \\ e-mail: dengqilin@sjtu.edu.cn \\ Chen Dianbing \\ School of Mechanical and Power Engineering \\ Shanghai Jiao Tong University \\ Shanghai, China \\ e-mail: chendianbing111@163.com
}

\begin{abstract}
Cast-iron parts are employed widely in all kinds of industries, which are very difficult to repair with overlaying welding methods such as electric arc,Ar arc, etc. Laser cladding is a great approach to repair this kind of parts. This paper did some experimental research of laser cladding reparations on the cast-iron parts. Growth rules of laser cladding layer has been studied through metallographic analysis. Powder gradient variation technology has been taken to solve the problem of tendency of cracks in the cladding layer, and the qualified strength and hardness are also acquired. Based on the success of experimental research, the laser cladding reparation technology is successfully applied inthe cast-iron mold in auto ind ustry.
\end{abstract}

Keywords-cast-iron parts; laser cladding reparation; mold in auto industry

\section{INTRODUCTION}

Cast-iron parts are widely used in all kinds of industries. After serving for a while, due to erosion and abrasion, they can't continue working and need reparation. But it's difficult to repair them because of their high content of carbon. Regular reparation methods such as electric, Ar and plasma arc overlaying welding can't be applied in the reparation because these methods require huge heat input and need preheat cast-iron to very high temperature which will definitely lead to deformation. Laser cladding is a very good reparation approach which is suitable for cast-iron parts.

Laser cladding reparation system mainly comprises computer, powder feedingsystem, laser machine, NC table. Laser beam irradiates cast-iron substrate to generate molten pool. Metal power is carried to molten pool via power feeding system and nozzle. A thin cladding layer is generated via substrate's movement in X-Y plane. After one layer has been formed, laser head and the nozzle which is mounted on the laser head make a Z-direction movement with a given distance to clad one more layer. In this way, cladding layer by layer to accomplish the reparation of the entire part. Then the final dimensions can be acquired by machining. In order to avoid the oxidation, the molten pool is usually protected by inert gas. The process of laser cladding reparation is illustrated as Fig.1.

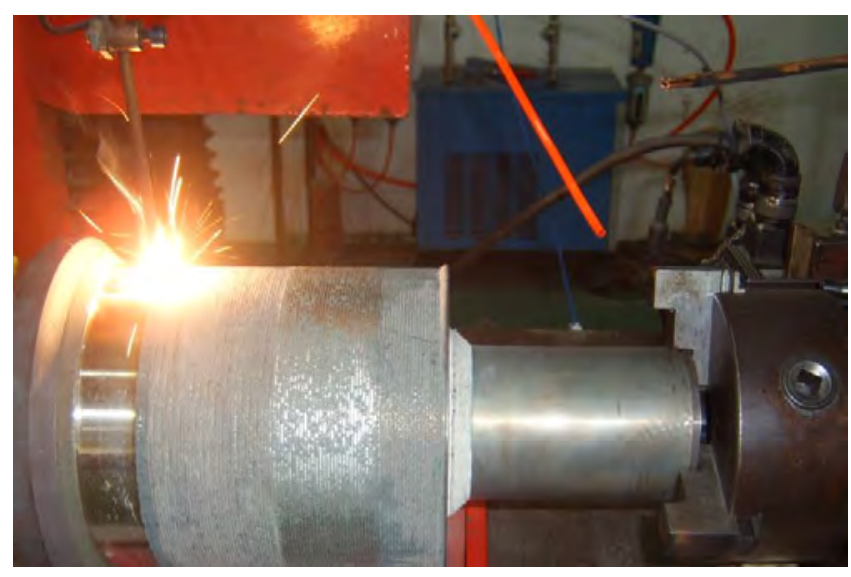

Figure 1. Laser cladding reparation process

Laser cladding reparation technology has many unique advantages: due to the metallurgic bonding between the cladding layer and the substrate, the combination has great strength and can bear server shock and vibration; the heat input is concentrate, the heat influential area is very small so it only causes substrate's tiny deformation or even no deformation; there are many kinds of powder usable for laser cladding and by allocating different powers to form new alloy powder, it is applicable for reparations of parts 
in all kinds of working conditions; since laser cladding reparation is controlled by computer, the quality of reparation can be guaranteed with the stable reparation process; the parts after laser cladding reparation have a much longer life-span because the performance of alloy powder used in cladding is better than that of the substrate material in all aspects.[1] [12]

This paper first talks about the laser cladding reparation experiment on cast-iron test-piece, then on the basis of the experiment, introduces the engineering application of laser cladding reparation on the cast-iron parts.

\section{EXPERIMENTAL MATERIALS AND PROCESS}

The substrate is cast-iron and the content is shown as Table1. The dimension of the test-piece is $100 \mathrm{~mm} \times 80 \mathrm{~mm} \times 20 \mathrm{~mm}$. Fe-based alloy powder is chosen as cladding powder, with granularity is -150 meshes +300 meshes, and its content is shown as Table 2 .

Table 1. The contents of QT600-3(wt\%)

\begin{tabular}{|c|c|c|c|c|c|}
\hline \multirow{2}{*}{ Element } & \multicolumn{5}{|c|}{ The contents of QT600-3 } \\
\cline { 2 - 6 } & $\mathrm{C}$ & $\mathrm{Si}$ & $\mathrm{Mn}$ & $\mathrm{S}$ & $\mathrm{P}$ \\
\hline Mass Fraction & 3.24 & 2.77 & 0.17 & 0.022 & 0.041 \\
\hline
\end{tabular}

Table 2. The contents of Fe-based alloy powder(wt\%)

\begin{tabular}{|c|c|c|c|c|c|c|c|}
\hline \multirow{2}{*}{ Element } & \multicolumn{7}{|c|}{ Fe-based alloy powder } \\
\cline { 2 - 8 } & $\mathrm{Cr}$ & $\mathrm{B}$ & $\mathrm{Si}$ & $\mathrm{Mo}$ & $\mathrm{Ni}$ & $\mathrm{C}$ & $\mathrm{Fe}$ \\
\hline $\begin{array}{c}\text { Mass } \\
\text { Fraction }\end{array}$ & $28-32$ & $1.5-2.5$ & $1.5-2.5$ & $3-4$ & $4-6$ & $3-3.5$ & $\mathrm{Bal}$ \\
\hline
\end{tabular}

The experiment employs a 5kw CO2 laser machine and an exclusive laser cladding powder feeding system, and takes synchronous powder feeding method. Before doing the cladding, the substrate is first burnished with 500\# metallographic abrasive paper to remove the rust and then washed by ethanol and acetone successively. The experimental parameters are: laser power 2000 2500w, scanning speed $5 \sim 10 \mathrm{~mm} / \mathrm{s}$, laser spot diameter $5 \sim 8 \mathrm{~mm}$, bead overlap $50 \%$, powder feeding rate $5 \sim 10 \mathrm{~g} / \mathrm{min}$, single layer depth $0.5 \sim 0.8 \mathrm{~mm}$. Ar is used as powder feeding gas and also to form the air curtain to protect the molten pool from the oxidation. In the experiment, single bead single layer cladding and multi-bead multi-layer cladding have been performed. Test pieces are cut off after the cladding process, and then burnished and polished. First corrode the substrate with nital and then corrode the cladding layer with ferric chloride and hydrochloric acid solution. Metallographic microscope has been used to observe the microstructure of the test pieces.

\section{EXPERIMENTAL OUTCOME AND ANALYSIS}

\section{A. multi-bead multi-layer laser cladding}

The test piece is displayed as Fig .2 and its microstructure is shown as Fig .3. The growth of the cladding layer is shown as Fig. 4 .

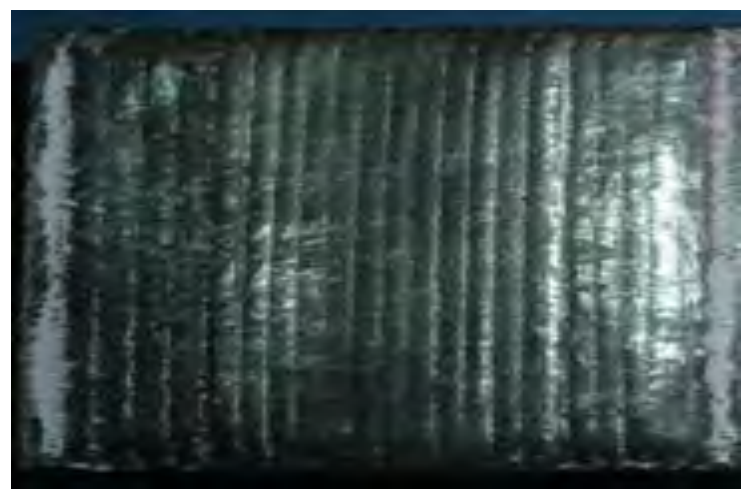

Figure 2. Macro appearance of the Fe based alloy cladding layer on the cast-iron test piece

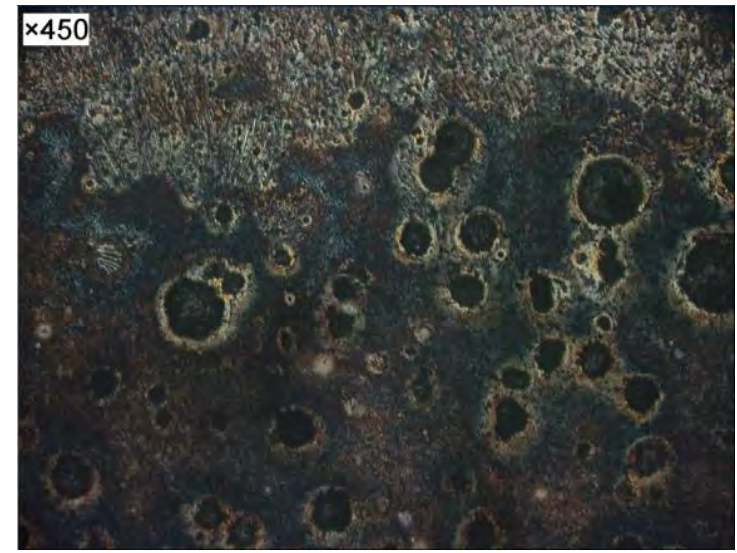

a. Cast-iron substrate structure

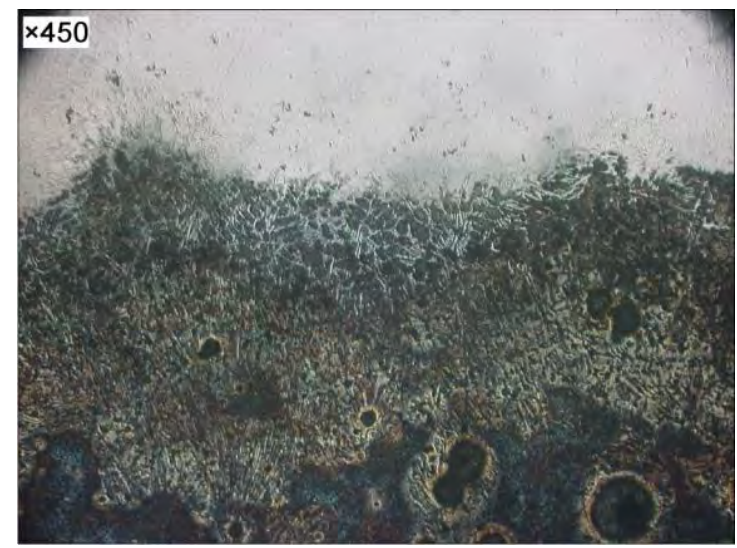

b. Combination area 


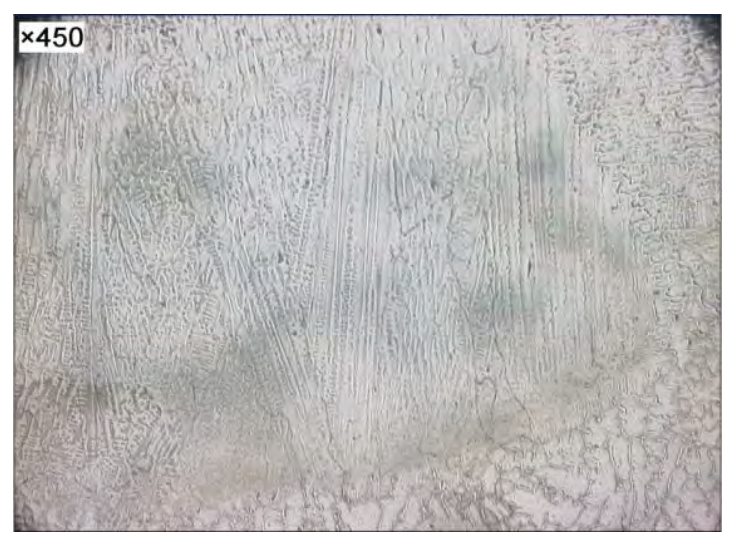

c. Fe alloy cladding layer

Figure 3. Microstructure of the cladding test piece

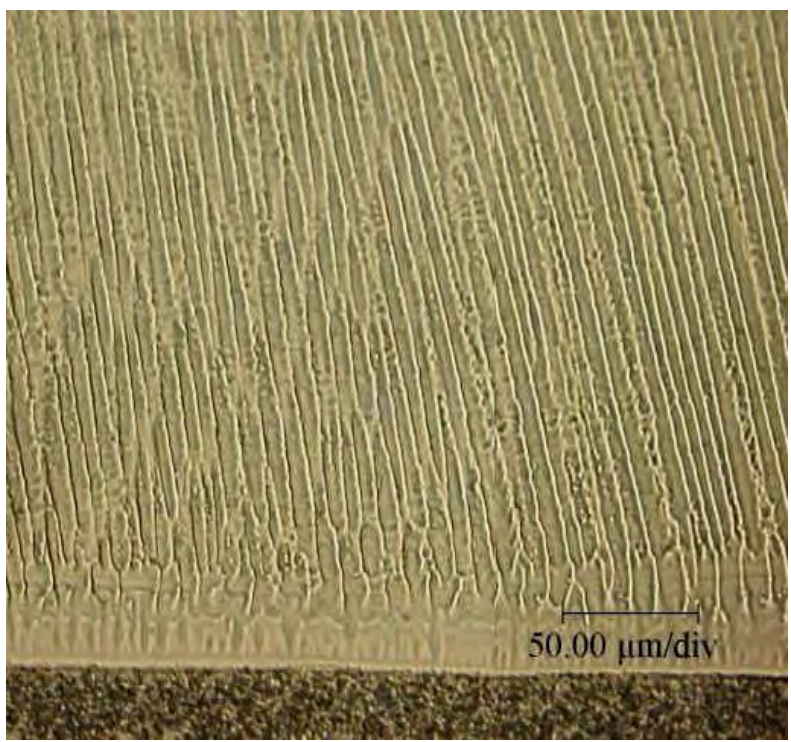

a. Interface of cladding layer and substrate

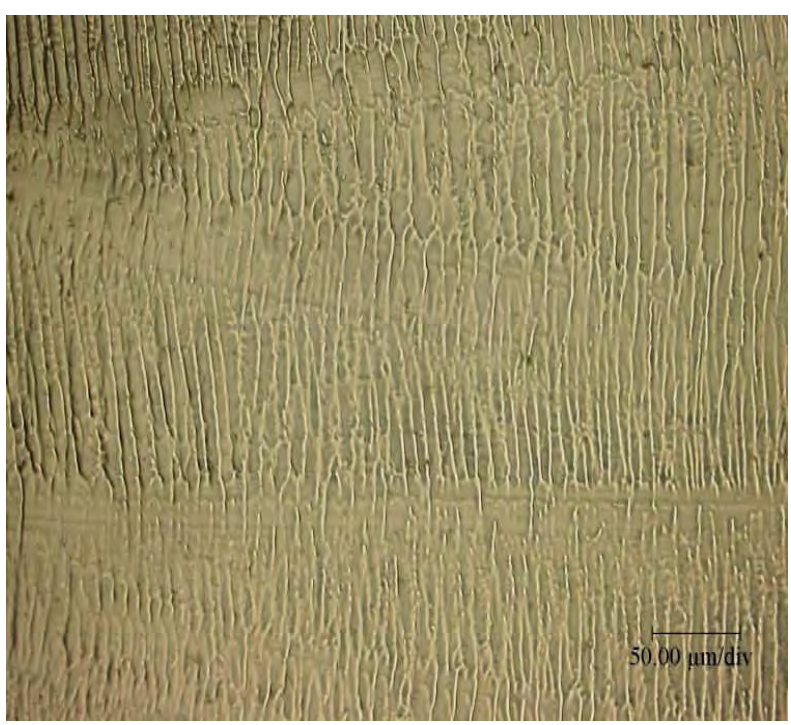

b. Bottom of cladding layer

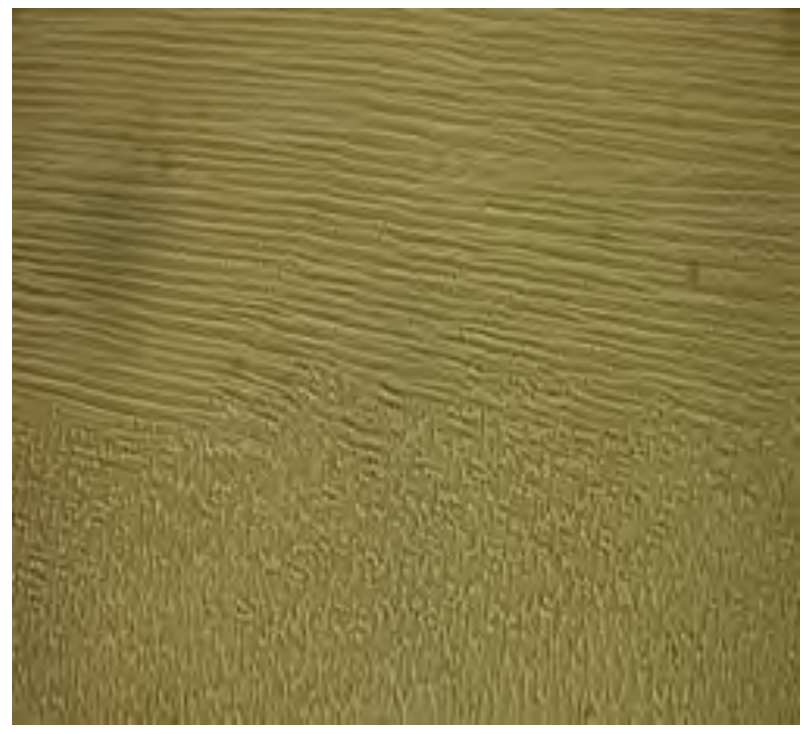

c. Top of cladding layer

Figure 4. Growth process of cladding layer

As we can see from the Fig .4, the liquid metal keeps connected with the solid substrate consistently during the cladding process. When the cladding process begins, the solid liquid interface area can acquire big temperature gradient because of the strong cooling influence of the substrate. The interface can be regarded as stable planar interface due to the very tiny wavelength of the interface unstable disturbance. The solidification of interface grows in the form of planar crystal. So the white planar crystal band has been formed between the cladding layer and substrate shown in Fig .4a, which indicates there is metallurgic bonding; the cladding layer dissipates its heat through substrate and the direction of the heat flow is perpendicular to the interface. In front of the interface there is pretty high temperature gradient which drives the columnar dendrite crystal to grow extensively. At the bottom of the cladding layer, perpendicular temperature gradient prevails greatly upon horizontal one. So the direction of the crystal growth is almost perpendicular to the surface of the substrate, which is shown in Fig .4b; as the cladding proceeds, the horizontal temperature gradient increases gradually while the vertical one decreases. They are almost equal in the middle of the cladding layer (the exact location is dependent on the process parameters). On the top of every cladding layer, horizontal temperature gradient dominates, and the growth direction of the crystal is close to horizontal, shown in Fig .4c.

\section{B. Gradient powder laser cladding}

Cladding $\mathrm{Fe}$ alloy directly on the cast-iron can lead tocrack(shown in Fig .5a because of the high content of C in the cast-iron parts (shown in Table 1). In order to avoid the crack between the cladding layer and substrate, and meet the high strength and hardness requirements of the surface of parts, gradient material powder has been taken 
into use. Alloy powder with good tenacity is applied in the bottom. Fe alloy powder is used in the surface. In this way, the crack can be avoided without substrate preheating. The experiment result is shown as Fig .5b.

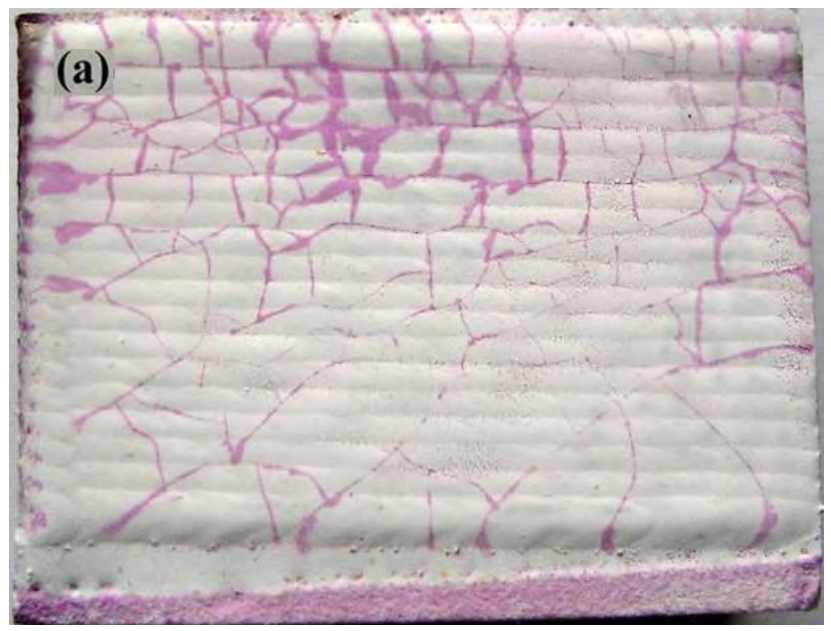

a. Crack of cladding Fe alloy

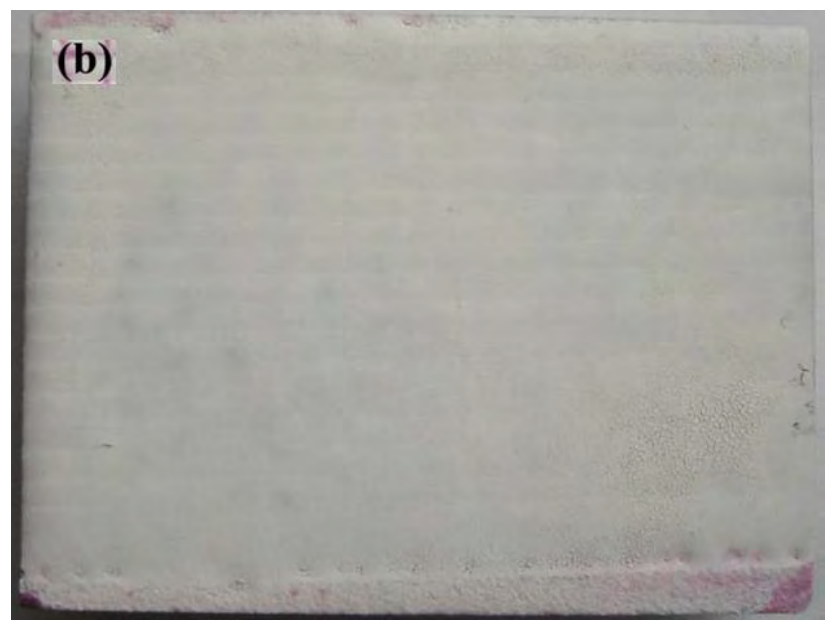

b. Avoid crack with cladding gradient materials

Figure 5. Laser cladding gradient material for reparation of cast-iron part

IV. ENGINEERING APPLICATION OF LASER CLADDING REPARATION IN AUTO CAST-IRON MOLD

Mold is important technological equipment in manufacturing industry. It's also widely used in auto manufacturing. Recently, cast-iron is widely used to make large stamping mold to replace steel. That's mainly because nodular cast iron is not only good in heat, abrasion and oxidation resistance, but also good in thermo mechanical properties and anti-fatigue. It can meet the materials requirements, improve product quality and reduce the production cost.

On the basis of the success of the above laser cladding reparation experiment, engineering application of the reparation in auto cast-iron mold has been carried out, which is illustrated as Fig .6-7.

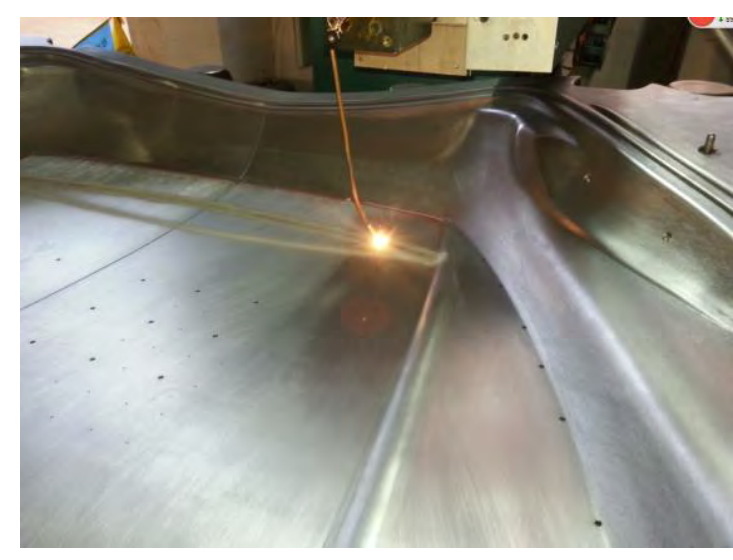

a. Before reparation

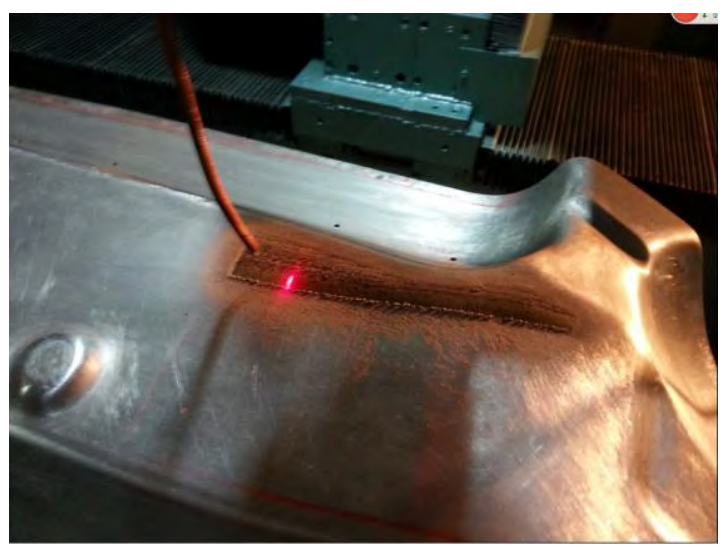

a. Before reparation

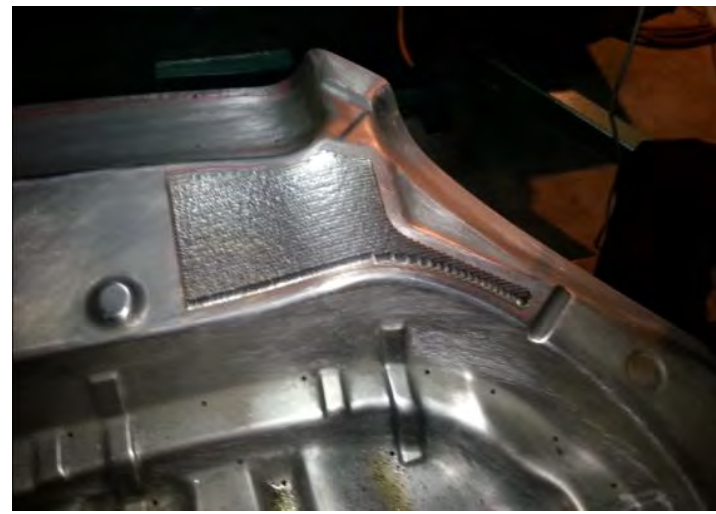

c. After reparation

Figure 6. Application of laser cladding reparation in auto cast-iron mold 


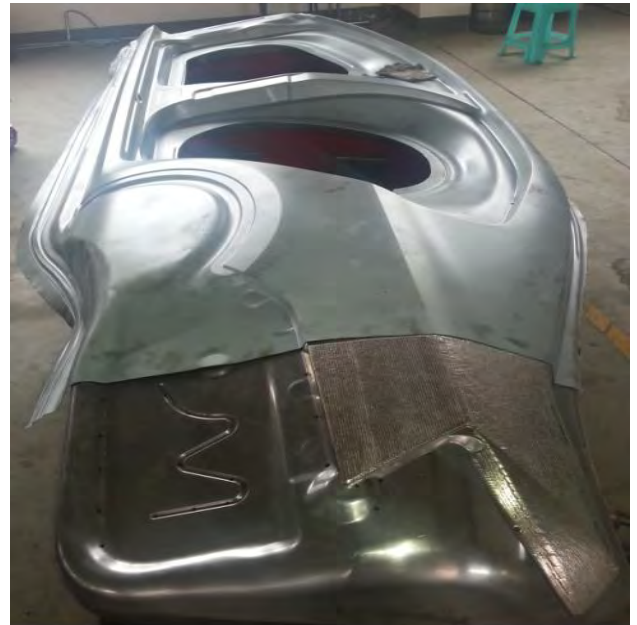

a. Laser cladding reparation

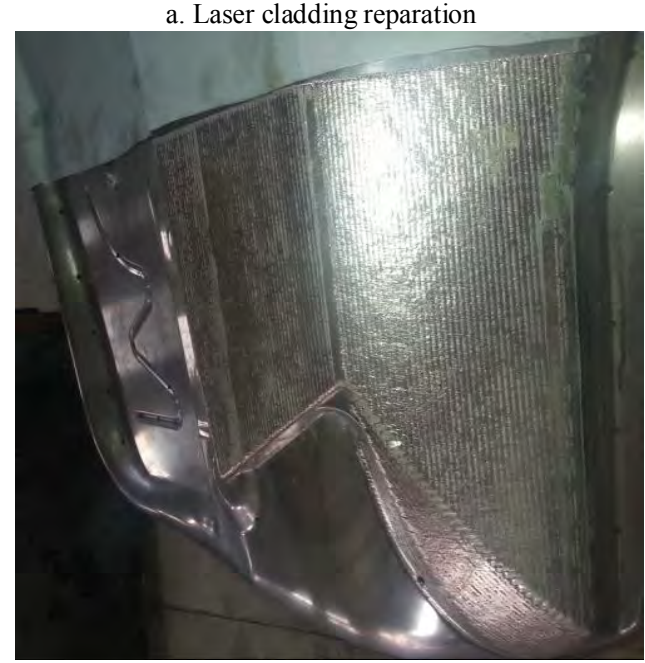

b. Enlarged scale photo

Figure 7. Cast-iron mold after laser cladding reparation

The laser cladding reparation of Auto cast-iron mold is implemented using gradient material powder. The thickness of part after cladding is larger than required. The mold accuracy is qualified after machining. The dye check indicates that there is no defect in the laser cladding layer.

\section{CONCLUSION}

(1)Laser cladding is a good approach in cast-iron part reparation. The metallurgic bonding is formed between cladding layer and substrate with the advantage of compact structure, tiny crystals, good performance, and little or even no deformation of repaired parts.

(2)Using gradient alloy powder to clad can form metallurgic bonding with fragile parts like cast-iron without cracks. The entire cladding layer has good performance, compact structure, and no defects. It can meet the high strength and hardness requirements of parts surface;

(3)Laser cladding reparation with gradient material powder technology has been taken into use to repair the auto cast-iron mold. After the machining and dye check, the repaired auto cast-iron mold is qualified for usage.

\section{ACKNOWLEDGMENTS}

This research was financially supported by the National Natural Science Foundation of China (No. 51275303).

\section{REFERENCES}

[1] WANG Sai-yu, X IONG Wei-hao. Applications of Laser Technology in Materials Science. Heat Treatment of Metals, 2005, 30(7): 32-36.

[2] ZHANG Kui-wu. Introduce on Materials, Processing Parameters, Microstructure and Properties of Foreign Laser Cladding. Heat Treatment of Metals, 2002, 27(6): 1-8

[3] Singh R, Kumar D, Mishra S K, et al. Laser cladding of Stellite 6 on stainless steel to enhance solid particle erosion and cavitation resistance. Surface and Coatings Technology, 2014, 250(7): 87-97.

[4] ZHU Wen-hui, XU Jiang, CHEN Zhe-yuan, et al. Study on the in situ TiB particle reinforced composite coating formed on 2024 aluminum alloy surface by laser cladding. Transactions of Materials and Heat Treatment, 2007, 28(S1): 222-227.

[5] XU Peng, LIN Cheng-xin, ZHOU Chao-Yu, et al. Preparation and microstructure of 304 stainless steel layer by laser cladding. Transactions of Materials and Heat Treatment, 2013, 34(7): 142 146

[6] XUE Min-peng, HAN Bin, WANG Yong, et al. Microstructures and Corrosion Resistance Properties of Ni-Based $\mathrm{WC} / \mathrm{Cr} 3 \mathrm{C} 2$ Coating Prepared by Laser Cladding. Laser \& Optoelectronics Progress, 2011, 48(9):85-90.

[7] CAI Zhen-bing, ZHU Min-hao, LIU Jun. Wear Characteristics of Laser Cladding Layers of $\mathrm{Ni60}$ and $\mathrm{Co}-\mathrm{Cr}-\mathrm{W}$ Alloy at High Temperature. Lubrication Engineering, 2006, (4): 26-28.

[8] LU Cheng, LIU Jiangwen, MA Wenyou, et al. Microstructure and High-Temperature Wear Resistance of Laser Cladding NickelBased Alloy Coating. Journal of Materials Protection, 2012, 45(2): $1-4+84$

[9] Zhong Min-lin, Liu Wen-jin. Leading Areas and Hot Topics on Global Laser Materials Processing Research[J]. Chinese Journal of Lasers. 2008,35(11): 1653-1659.

[10] Huang Yongjun, Zeng Xiaoyan . Microstructure and interface interaction in laser induction hybrid cladding of Ni-based coating[J]. Applied Surface Science. 2009 (255) 3940-3945.

[11] Zhu Qingiin, Wang Xinhong, Qu Shiyao,et al.. Amorphization of Fe38Ni30Si16B14V2 surface layers by laser cladding[J]. Transaction of Nonferrous Metals Society of China. 2008(18): 270 273.

[12] DONG Shi-yun, MA Yun-zhe, XU Bin-shi,et al. Current Status of Material for Laser Cladding[J]. Materials Review,2006,20(6): 5-13. 